\title{
Enuresis: The Hidden Problem
}

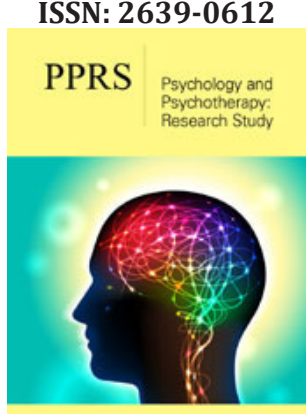

*Corresponding author: Sefa Bulut, Head of Counseling Psychology Department, Turkey

Submission: 盟 May 07, 2019

Published: 悳June 19, 2019

Volume 2 - Issue 3

How to cite this article: Sefa Bulut. Enuresis: The Hidden Problem. Psychol Psychother Res Stud. 2(3).PPRS.000540.2019. DOI: 10.31031/PPRS.2019.02.000540

Copyright@ Sefa Bulut, This article is distributed under the terms of the Creative Commons Attribution 4.0 International License, which permits unrestricted use and redistribution provided that the original author and source are credited.

\section{Sefa Bulut*}

Head of Counseling Psychology Department, Turkey

\begin{abstract}
Nocturnal enuresis is one of the most disabling conditions for both parents and children. Many children and their families are suffering this problem in their life. This can be a frustrating problem for children, entire family and the health care providers Gerson [1]. This can have a deep effect on children or adolescent's' behavior, emotional well-being and social life Hagglof [2]. It is one of the most common and chronic problems in childhoods and adolescents. Due to the nature of the problem, many parents and children are very reluctant to talk about the problem and seek help for that. Because of that, many children and adolescents suffer silently and cannot talk about their problems and seek solutions. Contrary to popular believe, this problem is not only specific to low social economic classes or developing countries. This can be observed in all over classes, nations, cultures and ethnic origins.
\end{abstract}

Keywords: Nocturnal enuresis

\section{Mini Review}

The problem of enuresis is as old as human history. There are written articles goes back as early as 1940, Miller [3] wrote about the bedwetting problem and later Hallgren [4] wrote about nocturnal enuresis and etiologic aspects of the problem. Since then there has been numerous publications about this topic and treatment solutions. Now, the scientific literature has accumulated huge amount of information, which provide very rich insights about the problem at hand. In fact, the enuresis happens in two distinct types, one-day time enuresis and the other one is while the children are sleeping, this type is called Nocturnal Enuresis. The child would wet the bed without knowing it, or without realizing it during the sleeping time. The wetting usually happens in the first 2 hours of the sleep, or sometimes this can happen more than once during a nighttime period.

A general description of nocturnal enuresis is: bedwetting is involuntary voiding the urine in the night during the sleep at the age 5 years or older Neveus [5]. DSM-IV-R APA [6] also requires the age of 5 or older along with at least 2 nights of bedwetting, and free of congenital or central nervous system problems. Before the age 5 , is somehow considered as a developmental issue and viewed more tolerantly. Nevertheless, after the age of 6 , children should be ready to seek some serious medical help and it is time for that Jackson [7].

Even though the prevalence rates of enuresis declines with age, it seems that in some cases it continues until further ages. Those after the age 10, are seems to be more severe and chronic cases. The majority of the cases continue throughout adolescence are very severe cases. Studies from different part of world shows that bedwetting is a universal phenomenon and independent of their cultural context (Butler \& Heron, 2008). There are other authors from East and West believes that, the prevalence rates and occurrences are very similar, and it happens every place regardless of culture and racial background De Sousa [8].

At age 5, 7\% male and 3\% females are enurectic, at age, $10 ; 3 \%$ of males and $2 \%$ females are enurectic. On the other hand, at the age of 18 , about $1 \%$ of males and less than $1 \%$ females suffer from enuresis Weintraub et al. [9]. In the same study, they found that obese males are 16 times more likely to suffer from enuresis than normal weight females.

It is not clear if the "chicken form the egg or egg from the chicken". Unfortunately, bedwetting is mistakenly seen as a "psychological" problem, which leads to further discrimination. Actually, in most cases the casual factor is a urinary infection or lack of antidiuretic hormone during the sleeping time Glass [10]. 
Genetic inheritance is among the most commonly cited etiological factors Schulpen [11]; Weintraub et al. [9] identified a positive family history as an increasing risk factor in Israeli children. Akis [12] study in Turkey, enuresis increased 11 times if mother or/and father had enuresis. There are other studies clearly shows that, once parents had the problem in their childhood, it is more likely that their offspring also would experience the same problems in sometime period in their life. Similar trend was also observed among siblings as well. However, even though in one family cancellation all of the children can have enuresis, in some families there is only one or two children would experience it. For those who experience the enuresis most probably they have more genetic similarities than the others do.

Butler [13] argued that enurectic children experience, feelings of different from others, feelings of quilt and shame, being at risk for humiliation and victimization by their friends. Similarly, children self-concept and self-esteem will also negatively be affected by their current problems. Therefore, enuresis may have a significant debilitating effect on enurectic children mental health Furthermore, Esposito [14] reported more educational problem in enurectics then the healthy children. The biggest problem was identified was being unable to maintain their concentrations in school and focus on their task. They have also reading difficulties.

Enuresis has great effect on children social life. Because of this condition, children and adolescence cannot plan overnight activities, they will always fear of wetting the beds even if they did not wet every day. They develop an anticipation anxiety for future wetting; therefore, they can be in a constant fear and anxiety. They may also will be discomphortable by their situations that their friends or classmate could figure out their conditions. For them, it is a very fragile position to be and continue their life, with limited social occasions.

Goin [15], informs that enurectic children cannot or do not participate age-appropriate activities such as sleepovers with friends or relatives or overnight camp activities and school trips etc. Similarly, enurectic children usually avoids trips from home because of the fear of ridicule Glass [10]. Those children and their families are limited in a sense that they will be ashamed if their children wed the beds in inappropriate places. Nocturnal enuresis has negative influence on children everyday life and activities, family vocations and children plan and programs in overnight stay in their friend's home Morrison [16].

Nocturnalenuresis now considered a treatable medical condition rather than a social problem Mithani [17]. In fact, psychological therapy produces better results than pharmacotherapy, but less appealing for the parents due to the fear of the child being labeled with psychologically disturbed. Another reason for not seeking help is social and peer pressure including in routine medical checkups Ward-Smith [18].

\section{Conclusion}

In conclusion it may be a "wait and see" is not an acceptable attitude Kanaheshwari [19]. Parents and caregivers should be more open-minded and seek help for the conditions. It is not something that they or their children should be ashamed of. Similarly, pediatricians and general physicians should be more careful when they are examining young children and may be ask some additional questions along with current problems. Mental health professions, school counselor, schoolteacher and people who are involved in children life, such as camp counselors or trip planners should be careful, open-minded and sensitive in case they may have enuresis children in their care or group [20].

Educational programs are also important for parents and enurectic children friend. Education programs could open their eyes and help them develop understanding and awareness. Therefore, it should be included in school counseling programs.

\section{References}

1. Gerson AC (2001) Editorial comment. Urology 58(5): 776.

2. Hagglof B, Andren O, Bergstrom E, Marklund L, Wendelius M (1998) Selfesteem in children with nocturnal enuresis and urinary incontinence: Improvement of self-esteem after treatment. Eur Urol 33(3): 16-19.

3. Miller E (1940) The bedwetting problem. Mental Health 1(1): 2-5.

4. Hallgren B (1958) Nocturnal enuresis; Aetiologic aspects. Acta Paediatrica 48(118): 66-74.

5. Nevéus T, Von Gontard A, Hoebeke P (2006) The standardization of terminology of lower urinary tract function in children and adolescents: Report from the standardisation committee of the international children's continence society. J Urol 176(1): 314-324.

6. (2000) American psychiatric association. Diagnostic and statistical manual of mental disorders. (DSM-IV-TR), ( $4^{\text {th }}$ edn). American Psychiatry Press, Washington, USA, pp. 74-75.

7. Jackson EC (2009) Nocturnal enuresis: Giving the child a "lift". The J Pediatr 154(5): 636-637.

8. De Sousa A, Kapoor H, Jagtap J, Sen M (2007) Prevalence and factors affecting enuresis amongst primary school children. Indian Journal of Urology 23(4): 354-357.

9. Weintraub Y, Singer S, Alexander D, Hacham S, Menuchin G, et al. (2013) Enuresis an unattended comorbidity of childhood obesity. Int J Obes 37(1): 75-78.

10. Glass N (1999) Austria tries "holiday-camp" treatment for bedwetting. The Lancet 354: 230.

11. Schulpen TW (1997) The burden of nocturnal enuresis. Acta Pediatrica 86(9): 981-984.

12. Akis N, Irgil E, Aytekin N (2002) Enuresis and the effective factors: a case-control study. Scandinavian Journal of Urology and Nephrology 36(3): 199-203.

13. Butler RJ (1998) Annotation: night wetting in children: psychological aspect. Journal of Child Psychology and Psychiatry 39(4): 453-463.

14. Esposito N, Carontenuto M, Rocella M (2011) Primary nocturnal enuresis and learning disability. Minerva Pediatrica 63(2): 99-104.

15. Goin RP (1998) Nocturnal enuresis in children. Child: Care, Health \& Development 24: 277-288.

16. Morision JM (1998) Parent's and young people's attitude towards bedwetting and their influence on behavior, including readiness to engage in and persist with treatment. Br J Urol 81: 16-68.

17. Mithani S, Zaidi Z (2005) Bed-wetting in schoolchildren of Karachi. J Pak Med Assoc 55(1): 2-5. 
18. Ward-Smith P, Barry D (2006) The challenge of treating enuresis. Uro Nurs 26(3): 222-224.

19. Kanaseshwari Y (2010) Research Letters. Journal of Tropical Pediatrics 57(2): 141.
20. Butler RJ, Heron J (2008) The prevalence of infrequent bedwetting and nocturnal enuresis in childhood. Scandinavian Journal of Urology and Nephrology 42(3): 257-264.

For possible submissions Click below:

Submit Article 